\title{
Do Maternal Blood Parameters Affect Fetal Birth Weight?
}

\author{
(D) Simten Genç, (D) Erhan Aktürk, (D) Başak Cıngıllıoğlu, (D) Melike Eren, (D) Hicran Acar Şirinoğlu, (D) Orhan Şahin, (D) Veli Mihmanlı \\ University of Health Sciences Turkey, Prof. Dr. Cemil Taşcıoğlu City Hospital, Clinic of Obstetrics and Gynecology Department, Istanbul, Turkey
}

\section{Abstract}

Objective: Perinatal morbidity and mortality increase significantly in newborns with low birth weight (LBW). Maternal total protein, albumin, hemoglobin ( $\mathrm{Hb}$ ), hematocrit (Hct), red blood cell (RBC), and electrolyte values may affect the birth weight of the baby.

Methods: This study included 363 pregnant women who consulted the Gynecology Department of Okmeydani Training and Research Hospital between July 2018 and December 2018 and gave birth between 37 and 42 gestational weeks. Newborns were divided into three groups: $\leq 2500$ g, 2500-4000 g, and $\geq 4000 \mathrm{~g}$. The relationship between birth weight and maternal Hb, Hct, RBC, total protein, albumin, and electrolytes values taken just before birth was examined.

Results: No significant difference was found between the three groups in terms of gravida, parity, abortus numbers, gestational weeks and age of the patients, maternal blood total protein, albumin, $\mathrm{Hb}$, Hct, calcium, sodium, potassium, and chloride values. RBC values were significantly lower in the $\leq 2500$ g group $(p=0.046)$, whereas maternal blood magnesium values were significantly higher $(p=0.026)$. When the relationship between severe anemia and fetal weight was examined, LBW was significant in the group with $\mathrm{Hb}<7.4$ ( $p=0.004$ ).

Conclusion: Maternal RBC levels were low, but magnesium levels were high in pregnant women who gave to LBW infants, and the LBW rate was high in the group with severe anemia. However, possible physiological changes that occur during pregnancy should be considered.

Keywords: Fetal birth weight, maternal anemia, maternal albumin, maternal electrolytes, maternal protein, maternal red blood cell

\section{INTRODUCTION}

Healthy nutrition during pregnancy aims for the birth of a healthy fetus that has reached term and for a good lactation process after birth.

A baby's weight at birth is affected by many social, economic, genetic, maternal, and environmental factors. Perinatal morbidity and mortality increase significantly in newborns with low birth weight (LBW). Although the LBW rate is as low as 6-7\% in all newborns, $2 / 3$ of all neonatal deaths occurred in babies with LBW (1).

Fetal birth weight is dependent on many factors related to the mother, such as height, pre-pregnancy weight, body mass index, weight gained during pregnancy, and number of calories in their diet. Studies have suggested that maternal total protein and albumin levels and maternal anemia may be effective in determining LBW. However, only a few studies have shown the relationship between maternal blood electrolyte levels and obstetric outcomes (2).

Maternal nutrition is extremely important, both for the fetus and the mother. Rates of fetal anomalies, abortus, stillbirth, LBW, and perinatal mortality increase in maternal malnutrition conditions. Especially for newborns with LBW, possible risk factors include low pre-pregnancy body mass index, maternal malnutrition, smoking, and alcohol consumption, which may then cause impaired growth and cognitive functions in later years (3).

In this study, we investigated the effect of total protein, albumin, hemoglobin $(\mathrm{Hb})$, hematocrit $(\mathrm{Hct})$, red blood cell $(\mathrm{RBC})$, and electrolyte values on the birth weight of term newborns. 


\section{METHODS}

This study included 363 pregnant women who consulted the Gynecology Department of Okmeydani Training and Research Hospital between July 2018 and December 2018 and gave birth between 37 and 42 gestational weeks. Patients with maternal systemic disease, maternal TORCH group of infectious diseases, diabetes mellitus, gestational diabetes, preeclampsia, smoking habits, and multiple pregnancies were not included. Blood was drawn from patients just before birth, and their $\mathrm{Hb}, \mathrm{Hct}, \mathrm{RBC}$, total protein, albumin, sodium, potassium calcium, magnesium, and chloride values were examined. In each case, gravida, parity, abortus numbers, age, gestational week, birth weight, fetal sex, and delivery type were recorded. Macrosomia was defined as fetal weight $>4000$ $\mathrm{g}$, and LBW as fetal weight $<2500 \mathrm{~g}$. After birth, newborns were divided into three groups: $\leq 2500 \mathrm{~g}, 2500-4000 \mathrm{~g}$, and $\geq 4000 \mathrm{~g}$.

Pregnant women with $\mathrm{Hb}$ levels M11 g/dL and Hct levels $<33$ were evaluated as "anemic". Additionally, all values were examined in three groups, which were determined as $(\mathrm{Hb}<7.4)$, $(7.4 \leq \mathrm{Hb} \leq 9.5)$, and $(\mathrm{Hb}>9.5)$, to showcase the degree of anemia present.

Pregnant women with total protein levels $<6.4 \mathrm{~g} / \mathrm{dL}$ were considered "hypoproteinemic", while those with albumin levels $<3.4 \mathrm{~g} / \mathrm{dL}$ were considered "hypoalbuminemic".

This study was performed in line with the principles of the Declaration of Helsinki. Approval was granted by the Ethics Committee of the University of Health Sciences Turkey, Prof. Dr. Cemil Tascioglu City Hospital (date: 28/09/2020, no: 48670771514.10-335). Written informed consent was obtained from patients who participated in this study.

\section{Statistical Analysis}

All information obtained in the study was entered into SPSS version 25.0 (IBM Corp. Armonk, NY, USA). Descriptive statistics were used to calculate the frequency (n), percentage (\%), central tendency (mean, median, and mode), and dispersion (range, variance, standard deviation, maximum, and minimum) for each variable when appropriate. Continuous data were evaluated by the Kolmogorov-Smirnov test to establish that if they are parametric or non-parametric. Then, One-Way ANOVA test (parametric) or Kruskal-Wallis test (non-parametric) were used as appropriate if there were more than two groups. As a posthoc test, Tukey's test was used. The chi-squared test was used in categorical variables. Pairwise comparisons with adjusted $p$ values (Bonferroni method) were applied as the post-hoc test in significant factors identified in the chi-square test. A p value $<0.05$ was considered significant.

\section{RESULTS}

In this study, 43 pregnant women (11.84\%) who gave birth to infants with birth weight $<2500 \mathrm{~g}$ (group 1), 273 pregnant women (75.20\%) who gave birth to infants with birth weight between 2500 and $4000 \mathrm{~g}$ (group 2), and 47 pregnant women (12.94\%) who gave birth to infants with birth weight $>4000$ g (group 3) were included. Demographic characteristics and obstetric results are shown in Table 1. No significant difference was found between the three groups in terms of gravida, parity, and abortion numbers. No significant difference was noted between the weeks of gestation and ages of the patients $(p=0.101$ and $p=0.251$, respectively). The rate of delivering a male baby in group 3 was significantly higher than that in the other two groups $(p<0.001$; difference was between group 1 and group 3 and between group 2 and group 3). Regarding delivery types, the rate of cesarean section in group 1 were significantly higher than that in the two groups $(p<0.001$, difference was between group 1 and group 2, between group 1 and group 3, and between group 2 and group 3). No significant difference was found between the three groups upon the examination of the maternal blood total protein, albumin, $\mathrm{Hb}$, Hct, calcium, sodium, potassium, and chloride values (Table 2). The difference between the RBC values among the three groups was significant (One-Way ANOVA, $p=0.046$ ). In the post-hoc tests, this difference was between group 1 and group 3 (Tukey test, $p=0.048$ ). $R B C$ values in group 1 were lower than the values in group 3 . The difference between the maternal blood magnesium levels among the three groups was significant (One-Way ANOVA, $p=0.026$ ). In the post-hoc tests, the difference in magnesium levels was between group 1 and group 2 (Tukey test, $p=0.031$ ). Magnesium values in group 1 were higher than that in group 2.

The groups that comprised patients with $\mathrm{Hb}<11 \mathrm{~g} / \mathrm{dL}$ and $\mathrm{Hct}$ $<$ below 33 were re-examined to investigate the relationship between maternal anemia and birth weight. No significant difference was found between the three groups ( $p=0.494$, $p=0.731$, respectively). To examine the relationship between maternal hypoproteinemia and birth weight, the group with albumin levels $<3.4 \mathrm{~g} / \mathrm{dL}$ and total protein levels $<6.4 \mathrm{~g} / \mathrm{dL}$ was re-evaluated, and no significant difference was noted between the three groups ( $p=0.725, p=0.445$, respectively) (Table 3).

As regards the relationship between severe anemia and fetal weight, a fetal weight of $\leq 2500 \mathrm{~g}$ was significant in the group with $\mathrm{Hb}<7.4(\mathrm{p}=0.004)$ (Table 4). 


\section{DISCUSSION}

Observational studies have tried to examine the relationship between the amount of fat that the mother consumed during pregnancy and her gestational weight gain (4). In a review that included 200 articles, the relationship between maternal nutrition and birth outcome depended on biological, socioeconomic, and demographic factors (5).
With the physiological changes that occur during pregnancy, lipids, fat-soluble vitamins, and some carrier proteins increase; while the glomerular filtration increases, albumin, water-soluble vitamins, amino acids, and mineral levels decrease. The plasma volume starts to increase between the $6^{\text {th }}$ and $8^{\text {th }}$ weeks of pregnancy and reaches $1500 \mathrm{~mL}$ at the $34^{\text {th }}$ week (6). Although a deficiency in protein intake during pregnancy causes LBW in mice, sheep, and pigs, it is still debated in humans (7). $\mathrm{Hb}$,

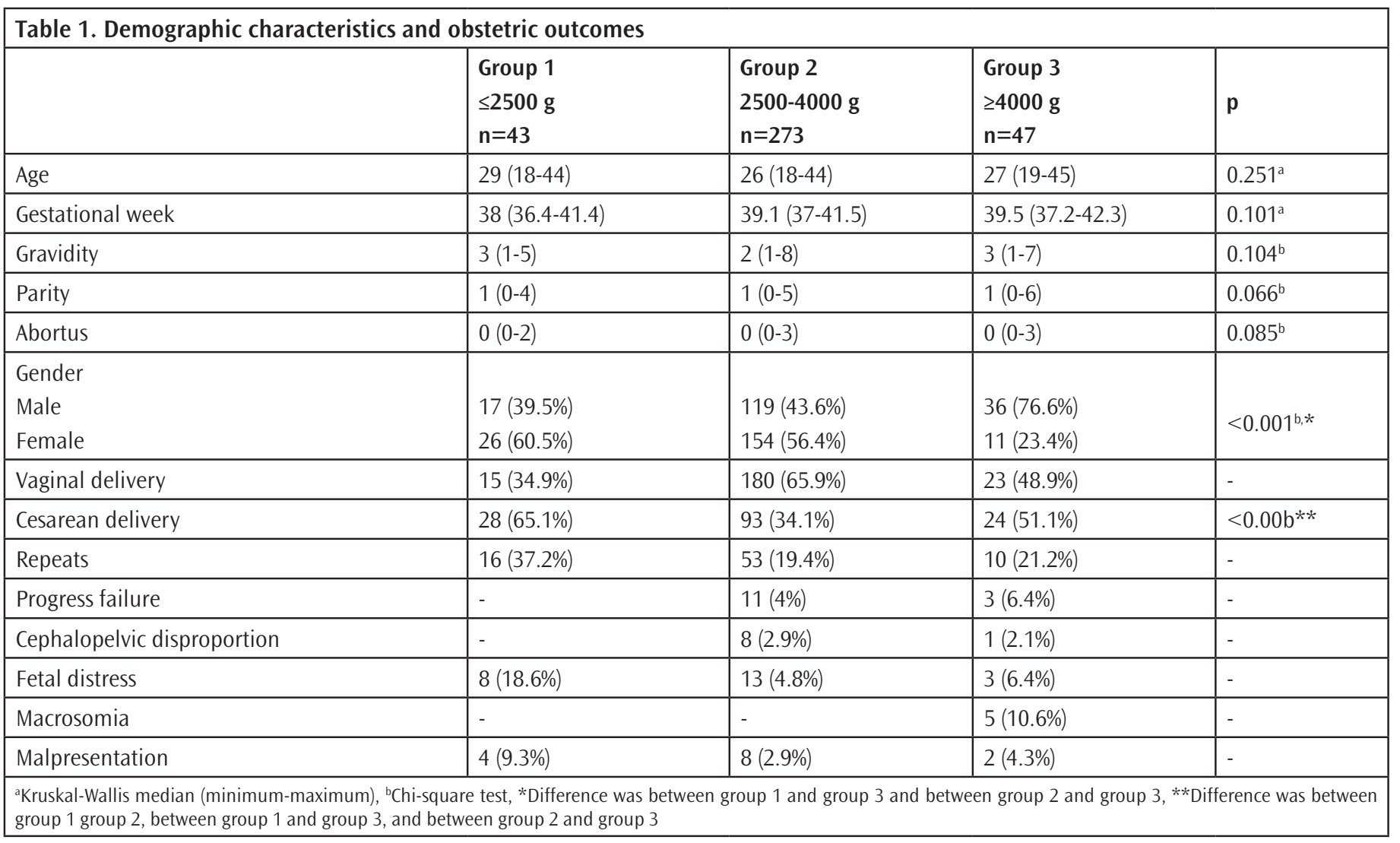

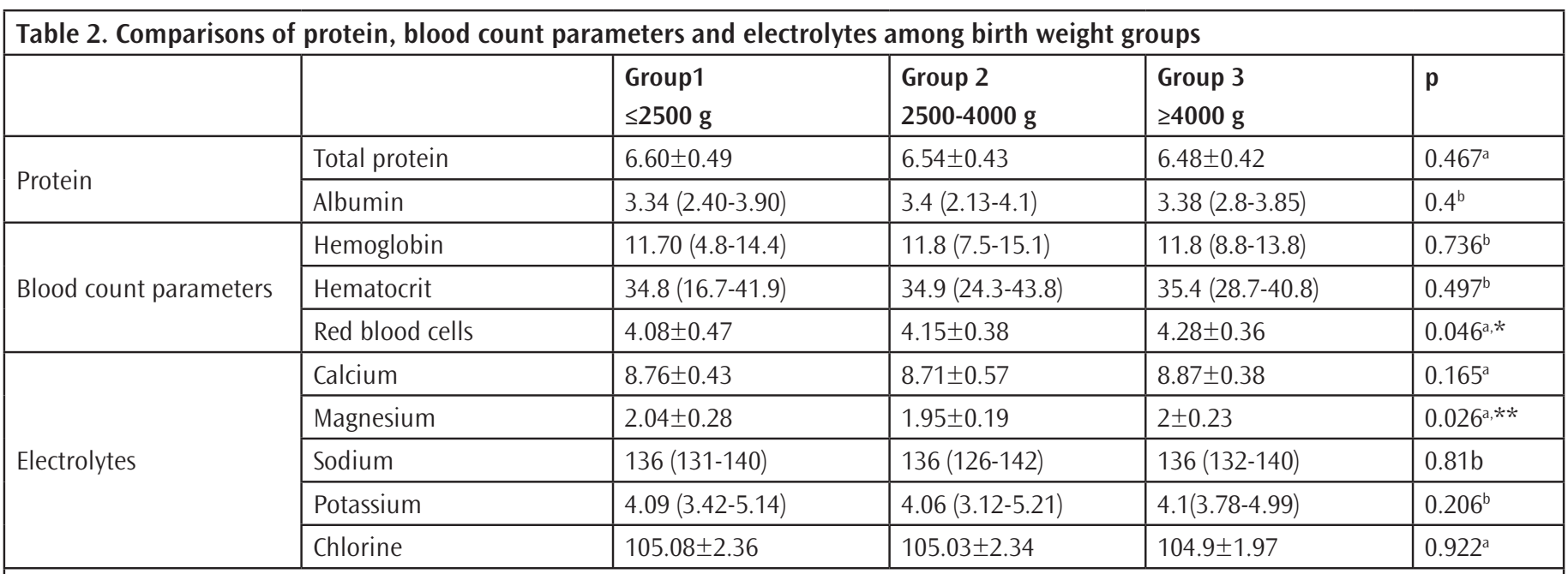

aOne-Way ANOVA [parametric-mean (standard deviation)], ${ }^{\mathrm{b}}$ Kruskal-Wallis [non-parametric-median (minimum-maximum)], *Difference was between group 1 and group 3 (Tukey test $p=0.048),{ }^{* *}$ Difference was between group 1 and group 2 (Tukey test $p=0.031$ ) 
Table 3. Comparison of anemia, hypoproteinemia, and hypoalbuminemia

\begin{tabular}{|c|c|c|c|c|c|}
\hline & \multicolumn{2}{|c|}{$\leq 2500 \mathrm{~g}$} & $2500-4000 \mathrm{~g}$ & $\geq 4000 \mathrm{~g}$ & $\mathbf{p}$ \\
\hline \multirow{2}{*}{ Hemoglobin } & $<11$ & 11 & 80 & 10 & \multirow{2}{*}{$0.494^{\mathrm{a}}$} \\
\hline & $\geq 11$ & 32 & 193 & 37 & \\
\hline \multirow{2}{*}{ Hematocrit } & $<33 \%$ & 11 & 73 & 10 & \multirow{2}{*}{$0.731^{\mathrm{a}}$} \\
\hline & $\geq 33 \%$ & 32 & 200 & 37 & \\
\hline \multirow{2}{*}{ Albumin } & $<3.4$ & 24 & 136 & 25 & \multirow{2}{*}{$0.725^{\mathrm{a}}$} \\
\hline & $\geq 3.4$ & 19 & 137 & 22 & \\
\hline \multirow{2}{*}{ Total protein } & $<6.4$ & 14 & 99 & 21 & \multirow{2}{*}{$0.445^{\mathrm{a}}$} \\
\hline & $\geq 6.4$ & 29 & 174 & 26 & \\
\hline
\end{tabular}

\begin{tabular}{|l|l|l|l|}
\hline \multicolumn{4}{|l|}{ Table 4. Comparison of anemia levels* } \\
\hline $\mathrm{Hb}<7.4$ & Group 1 & Group 2 & Group 3 \\
\hline $7.4 \leq \mathrm{Hb} \leq 9.5$ & $2(4.7 \%)$ & 0 & 0 \\
\hline $\mathrm{Hb}: 9.5-11$ & $2(4.7 \%)$ & $15(5.5 \%)$ & $2(4.3 \%)$ \\
\hline $\mathrm{Hb}<7.4$ & $39(90.7 \%)$ & $258(94.5 \%)$ & $45(95.7 \%)$ \\
\hline *Chi-square test, $\mathrm{p}=0.004, \mathrm{Hb}:$ Hemoglobin \\
\hline
\end{tabular}

iron, and albumin levels were evaluated in a study conducted in Korean pregnant women, and the logistic regression analysis revealed that $\mathrm{Hb}$ and albumin levels had the most important predictive value in determining LBW (2).

During pregnancy, there is a physiological decrease in Hct levels because the increasing plasma volume is disproportionate to the erythrocyte volume. Normally, physiological hemodilution occurs in every pregnancy. Anemia during pregnancy was defined by the Centers for Disease Control and Prevention in $1989 \mathrm{as} \mathrm{Hb}$ value $<11 \mathrm{~g} / \mathrm{dL}$ or $\mathrm{Hct}<33 \%$ in the $1^{\text {st }}$ and $3^{\text {rd }}$ trimesters of pregnancy and $\mathrm{Hb}<10.5 \mathrm{~g} / \mathrm{dL}$ or $\mathrm{Hct}<32 \%$ in the second trimester. According to the World Health Organization in 2001, anemia during pregnancy is defined as $\mathrm{Hb}<11 \mathrm{~g} / \mathrm{dL}$ for all three trimesters $(8,9)$. In our study, we accepted the upper limit of the $\mathrm{Hb}$ value as $11 \mathrm{~g} / \mathrm{dL}$ and $\mathrm{Hct}$ as $33 \%$. Hb levels in the first trimester indicate maternal nutritional status and have a positive correlation with newborn weight. However, the effect of maternal hemodilution on fetal growth in the second and third trimesters is more important. Since there is insufficient hemodilution in pregnant women with chronic malnutrition, infants had LBW $(2,10)$.

In the present study, no relationship was found between $\mathrm{Hb}$ and Hct values and birth weight. Msolla and Kinabo (11) found a positive correlation between $\mathrm{Hb}$ levels in the last trimester and birth weight in their study. Thus, the rates were significant than those with $\mathrm{Hb}<7.4 \mathrm{gr} / \mathrm{dL}$ who gave birth to babies with weighing $<2500 \mathrm{~g}$, whereas those with $\mathrm{Hb}>9.5 \mathrm{gr} / \mathrm{dL}$ gave birth to babies with weighing $>3000 \mathrm{~g}$. Moreover, babies of mothers with anemia had lower birth weights than non-anemics (11). In the present study, the number of patients with severe anemia was significantly low. However, in accordance with the literature, the rate of newborns with LBW was significantly higher in those with $\mathrm{Hb}<7.4 \mathrm{~g} / \mathrm{dL}$. Besides, the rate of newborns weighing $>4000 \mathrm{~g}$ was higher in the group with $\mathrm{Hb}$ of 9.5-11 $\mathrm{g} / \mathrm{dL}$. In a randomized controlled study, iron replacement to pregnant women until the $28^{\text {th }}$ gestational week reduced LBW but did not prevent third-trimester anemia. Moreover, the authors stated that third-trimester anemia was not significant in determining the birth weight and that iron supplementation caused an increase in the birth weight of the baby by passing iron to the fetus (12). Studies have also stated that taking iron supplements during pregnancy causes oxidative damage $(2,13)$. In a study conducted on 622 pregnant women, a decrease of $21 \mathrm{~g}$ in newborn weight was observed with a $1 \mathrm{~g} / \mathrm{dl}$ decrease in maternal $\mathrm{Hb}$, and a relationship between maternal anemia and low/insufficient birth weight was found (14). In a study of 2006-2010 data in Finland, a relationship was found between maternal anemia and adverse perinatal outcome, especially in multiparous pregnant women. This relationship was not found in nulliparas (15).

RBCs are oxygen-carrying cells. Low RBC levels indicate anemia or blood loss, while their numbers increase with heavy exercise and high altitude. Drugs that cause hemolysis may also reduce the erythrocyte count. In our study, the pregnant women had no history of such drug use, but RBC counts were significantly lower in the LBW group and were significant.

Additional protein is required for the growth and development of the fetus, uterus, placenta, and breasts. Some authors reported that a woman giving birth at term has a daily protein requirement of $6 \mathrm{~g}$, and the amount of protein stored is between 925 and $1000 \mathrm{~g}$ (16). Studies have also revealed that birth weight increases in pregnancy women with high total protein and albumin levels and reported a relationship between large-forgestational-age newborns and low serum albumin levels $(17,18)$. However, some studies have reported that maternal albumin and protein levels do not affect fetal weight $(7,19,20)$. In our study, albumin and total protein levels did not affect fetal weight.

Pregnant women need 20-30 g of calcium in total. Most of this is stored in fetal bone in the late period of pregnancy and is mobilized for fetal development. Taking calcium supplements during pregnancy prevents low gestational weight, birth weight $<2500 \mathrm{~g}$, and infants' risk hypertension in the future 
by lowering the blood pressure of the fetus. Moreover, taking calcium supplements during pregnancy reduces pregnancyinduced hypertension only in women who receive a low amount of calcium (21). In previous studies, a significant relationship was found between neonatal weight and energy, protein, and calcium intake in the third trimester $(22,23)$. The 2007 Cochrane review covers 12 studies on calcium. Regarding calcium supplementation, a decrease in the risk of preeclampsia was reported in 12 studies and a decrease in the risk of high blood pressure was reported in 11 studies compared with placebo. Maternal death and serious morbidity risk decreased in four studies. No effect on preterm birth or stillbirth was found (24). In our study, no significant difference was observed in maternal calcium values between the LBW group and other groups. In a study investigating maternal calcium, zinc, iron, and magnesium levels, significantly higher values of electrolytes, except magnesium, were found in umbilical cords of babies with normal birth weight compared with the babies with LBW (25). In the Cochrane review of seven studies, oral magnesium supplements before 25 gestational weeks decreased the frequency of preterm births, infants small for gestational age, and babies with LBW. In addition, the risk of hospitalization and antepartum hemorrhage was reduced in pregnant women. However, no studies have presented high-quality evidence to support the use of magnesium supplementation (26). In an animal study, magnesium restriction did not affect birth weight. However, if the restriction continued during the postnatal lactation period, the offspring is weaned and the bodyweight decreased (27). In our study, maternal blood magnesium level was significantly higher in the LBW group compared with the normal weight group.

Maternal plasma sodium concentrations decrease slightly as a result of pregnancy, and potassium concentrations do not change. A significant decrease was found in sodium, and potassium plasma levels in pregnant animals on a low-sodium diet increased (28). Moreover, pregnant rats on a low-sodium diet in the last 7 days of pregnancy experienced plasma expansion and fetal growth restriction. This study may be considered a simple animal model examining the relationship between maternal plasma volume and fetal growth (29). Chloride is the main anion in extracellular liquid and plays a role in the adjustment of osmotic pressure and anion-cation balance. Very few reports revealed the importance of chloride in pregnancy. Most studies are related to the amount of chloride in drinking water. In Italy, Fabiani et al. (30) examined the amount of chloride in drinking water and the obstetric outcome on pregnant women and did not find a relationship between LBW and preterm delivery. In addition, no relationship was found between maternal sodium, potassium, and chloride values and fetal weight in our patient group.

\section{CONCLUSION}

The effect of anemia, hypoproteinemia, and changes in maternal electrolyte levels on maternal and fetal outcomes should be evaluated according to etiology. In our study, maternal RBC levels were low, magnesium levels were high in pregnant women who gave birth with LBW, and the LBW rate was high in the group with severe anemia. Physiological changes that may occur during pregnancy should be given primary consideration. The interpretation of the results of our study is difficult because of differences in the characteristics, diagnostic criteria, and threshold value of the studied group of pregnant women. However, prospective studies with large patient groups and evaluations of all perinatal results are needed.

\section{Ethics}

Ethics Committee Approval: Ethics Committee of the University of Health Sciences Turkey, Prof. Dr. Cemil Tascioglu City Hospital (date: 28/09/2020, no: 48670771-514.10-335).

Informed Consent: Written informed consent was obtained from patients who participated in this study.

Peer-review: Externally peer-reviewed.

\section{Authorship Contributions}

Surgical and Medical Practices: S.G., E.A., B.C., M.E., H.A.S., O.S., V.M., Concept: S.G., E.A., M.E., V.M., Design: S.G., B.C., O.S., Data Collection or Processing: S.G., M.E., H.A.S., Analysis or Interpretation: S.G., E.A., B.C., Literature Search: S.G., B.C., V.M., Writing: S.G., H.A.S., O.Ş.

Conflict of Interest: No conflict of interest was declared by the authors.

Financial Disclosure: The authors declared that this study received no financial support.

\section{REFERENCES}

1. Guyer B, Freedman MA, Strobino DM, Sondik EJ. Annual summary of vital statistics: trends in the health of Americans during the 20th century. Pediatrics 2000;106:1307-17.

2. Lee HS, Kim MS, Kim MH, Kim YJ, Kim WY. Iron status and its association with pregnancy outcome in Korean pregnant women. Eur J Clin Nutr 2006;60:1130-5.

3. Fowles ER. Prenatal nutrition and birth outcomes. J Obstet Gynecol Neonatal Nurs 2004;33:809-22. 
4. Tielemans MJ, Garcia AH, Peralta Santos A, Bramer WM, Luksa N, Luvizotto MJ, et al. Macronutrient composition and gestational weight gain: a systematic review. Am J Clin Nutr 2016;103:83-99.

5. Tyagi S, Toteja GS, BhatiaN. Maternal nutritional status and its relation with birth weight. Int J Health Sci Res 2017;7:422-33.

6. Williamson CS. Nutrition in pregnancy. Nutrition Bulletin 2006;31:2859.

7. Thame M, Wilks RJ, McFarlane-Anderson N, Bennett FI, Forrester TE. Relationship between maternal nutritional status and infant's weight and body proportions at birth. Eur J Clin Nutr 1997;51:134-8.

8. World Health Organization. Iron deficiency anaemia assessment prevention and control: a guide for program managers. Geneva: World Health Organization, 2001. 132 (WHO/ NHD 01.3).

9. Breymann C. Iron deficiency anemia in pregnancy. Semin Hematol 2015;52:339-47.

10. Rosso P, Donoso E, Braun S, Espinoza R, Salas SP. Hemodynamic changes in underweight pregnant women. Obstet Gynecol 1992;79:908-12.

11. Msolla MJ, Kinabo JL. Prevalence of anaemia in pregnant women during the last trimester. Int J Food Sci Nutr 1997;48:265-70.

12. Cogswell ME, Parvanta I, Ickes L, Yip R, Brittenham GM. Iron supplementation during pregnancy, anemia, and birth weight: a randomized controlled trial. Am J Clin Nutr 2003;78:773-81.

13. Beard JL. Effectiveness and strategies of iron supplementation during pregnancy. Am J Clin Nutr 2000;71(5 Suppl):1288S-94S.

14. Figueiredo ACMG, Gomes-Filho IS, Batista JET, Orrico GS, Porto ECL, Cruz Pimenta RM, et al. Maternal anemia and birth weight: a prospective cohort study. PLoS One 2019;14:e0212817.

15. Räisänen S, Kancherla V, Gissler M, Kramer MR, Heinonen S. Adverse perinatal outcomes associated with moderate or severe maternal anaemia based on parity in Finland during 2006-10. Paediatr Perinat Epidemiol 2014;28:372-80.

16. Cunningham FG, Leveno KJ, Bloom SL, Huath JC, Gilstrap III LG, Wenstrom KD. Williams Obstetrics. 22nd ed. NewYork: McGRAW-HILL;2005. p.2139.

17. Sun JD, Shao YF, Zhang PL, Li DZ, Gu LY, Guo QN. Evaluation of prenatal nutrition counseling: maternal nutrition status and infant birthweight. Biomed Environ Sci 1990;3:458-65.

18. Hasin A, Begum R, Khan MR, Ahmed F. Relationship between birth weight and biochemical measures of maternal nutritional status at delivery in Bangladeshi urban poors. Int J Food Sci Nutr 1996;47:273-9.
19. Swain S, Singh S, Bhatia BD, Pandey S, Krishna M. Maternal hemoglobin and serum albumin and fetal growth. Indian Pediatr 1994;31:777-82.

20. Maher JE 3rd, Goldenberg RL, Tamura T, Cliver SP, Johnston KE, Hoffman $\mathrm{HJ}$. Indicators of maternal nutritional status and birth weight in term deliveries. Obstet Gynecol 1993;81:165-9.

21. Beinder E. Kalziumsupplementation in der Schwangerschaft--ein Muss (?) [Calcium-supplementation in pregnancy--is it a must?]. Ther Umsch 2007;64:243-7.

22. Khoushabi F, Saraswathi G. Impact of nutritional status on birth weight of neonates in Zahedan City, Iran. Nutr Res Pract 2010;4:339-44.

23. Moghaddam Tabrizi F, Saraswathi G. Maternal anthropometric measurements and other factors: relation with birth weight of neonates. Nutr Res Pract 2012;6:132-7.

24. Hofmeyr GJ, Lawrie TA, Atallah AN, Duley L, Torloni MR. Calcium supplementation during pregnancy for preventing hypertensive disorders and related problems. Cochrane Database Syst Rev 2014;CD001059.

25. 25-Khoushabi F, Shadan MR, Miri A, Sharifi-Rad J. Determination of maternal serum zinc, iron, calcium and magnesium during pregnancy in pregnant women and umbilical cord blood and their association without come of pregnancy. Mater Sociomed 2016;28:104-7.

26. Makrides M, Crosby DD, Bain E, Crowther CA. Magnesium supplementation in pregnancy. Cochrane Database Syst Rev 2014;2014:CD000937.

27. Raghunath M, Venu L, Padmavathi I, Kishore YD, Ganeshan M, Anand Kumar K, et al. Modulation of macronutrient metabolism in the offspring by maternal micronutrient deficiency in experimental animals. Indian J Med Res 2009;130:655-65.

28. Kirksey A, Pike RL, Callahan JA. Some effects of high and low sodium intakes during pregnancy in the rat. II. Electrolyte concentrations of maternal plasma, muscle, bone and brain and of placenta, amniotic fluid, fetal plasma and total fetus in normal pregnancy. J Nutr 1962;77:43-51.

29. Roy-Clavel E, Picard S, St-Louis J, Brochu M. Induction of intrauterine growth restriction with a low-sodium diet fed to pregnant rats. Am J Obstet Gynecol 1999;180:608-13.

30. Fabiani L, Materazzo F, Ensabella F, Giuliani AR, Patacchiola F, Oleandri V, et al. Basso peso alla nascita, abitudini di vita delle madri in gravidanza e consumo di acque sottoposte a clorazione [Low birth weight, life style of mothers during pregnancy and chlorinated drinking water]. Ann Ig 2003;15:933-43. 